\title{
P088: Monitoring multiresistant bacteria (MRB) to Principal Hospital Dakar: assessment of 1 year
}

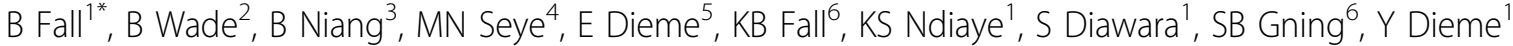 \\ From 2nd International Conference on Prevention and Infection Control (ICPIC 2013) \\ Geneva, Switzerland. 25-28 June 2013
}

\section{Introduction}

Bacterial resistance to antibiotics is a public health problem. Mastering their distribution is thus a priority. Thus, at the Principal Hospital of Dakar (HPD), a system for collecting and analyzing data of resistance has been established within the Committee against nosocomial infections.

\section{Objectives}

We present here the results compiled over a year to help guide prevention activities.

\section{Methods}

Prospective study from January 1 to December 31, 2012 at the HPD. Every day, multiresistant bacteria isolated in the laboratory are subject to a collection of clinical and biological data using a questionnaire. Enterobacteriaceae producing extended-spectrum beta-lactamase (ESBL) and derepressed cephalosporinases of Pseudomonas aeruginosa, multiresistant Acinetobacter and Methicillin Resistant Staphylococcus aureus isolates were analyzed. The data are then analyzed by Epi info.

\section{Results}

323 BMR were collected during the study period. The average age was 32 years [ 4 days, 95 years] and the sex ratio was 1.70. ESBL-producing Enterobacteriaceae (80\%) followed by Acinetobacter multiresistant respectively (11\%), ticarcillin-resistant Pseudomonas aeruginosa (4\%) and methicillin-resistant Staphylococcus aureus (4\%) were the most common isolates. ESBLs were as follows: 55\% Klebsiella, E. coli 32\% 11\% Enterobacter, and others $2 \%$. Blood cultures were the most common samples $(40 \%)$, followed respectively by urinary tract infections (37\%) and abscesses (16\%). The pediatrics department was most affected (45\%), followed respectively by the Internal Medicine and Resuscitation (each 23\%) and Surgery (9\%). A catheter was present in $91 \%$ of patients with sepsis and $66 \%$ of ESBL infections ESBL-producing Enterobacteriaceae were considered nosocomial.

\section{Conclusion}

This study shows the important place occupied by multiresistant bacteria Principal Hospital. ESBL-producing Enterobacteriaceae represent the most common resistant organisms, mainly in the form of nosocomial infections.

\section{Disclosure of interest}

None declared.

\section{Author details}

${ }^{1}$ Laboratories Federation, Dakar, Senegal. ${ }^{2}$ Directorate, HPD, Dakar, Senegal. ${ }^{3}$ Reanimation Department, HPD, Dakar, Senegal. ${ }^{4}$ Pediatrics, HPD, Dakar, Senegal. ${ }^{5}$ Surgical Services, HPD, Dakar, Senegal. ${ }^{6}$ Medical Services, HPD, Dakar, Senegal.

Published: 20 June 2013

doi:10.1186/2047-2994-2-S1-P88

Cite this article as: Fall et al:: P088: Monitoring multiresistant bacteria (MRB) to Principal Hospital Dakar: assessment of 1 year. Antimicrobial Resistance and Infection Control 2013 2(Suppl 1):P88.

${ }^{1}$ Laboratories Federation, Dakar, Senegal

Full list of author information is available at the end of the article

(c) 2013 Fall et al; licensee BioMed Central Ltd. This is an Open Access article distributed under the terms of the Creative Commons 